\title{
Circulating Estradiol Regulates Brain-Derived Estradiol via Actions at GnRH Receptors to Impact Memory in Ovariectomized Rats
}

\author{
Britta S. Nelson, ${ }^{1}$ Katelyn L. Black, ${ }^{1,2}$ and Jill M. Daniel ${ }^{1,2,3}$
}

DOI:http://dx.doi.org/10.1523/ENEURO.0321-16.2016

${ }^{1}$ Neuroscience Program, Tulane University, New Orleans, LA 70118, ${ }^{2}$ Brain Institute, Tulane University, New Orleans, LA 70118, and ${ }^{3}$ Department of Psychology, Tulane University, New Orleans, LA 70118

\begin{abstract}
Systemic estradiol treatment enhances hippocampus-dependent memory in ovariectomized rats. Although these enhancements are traditionally thought to be due to circulating estradiol, recent data suggest these changes are brought on by hippocampus-derived estradiol, the synthesis of which depends on gonadotropin-releasing hormone $(\mathrm{GnRH})$ activity. The goal of the current work is to test the hypothesis that peripheral estradiol affects hippocampus-dependent memory through brain-derived estradiol regulated via hippocampal $\mathrm{GnRH}$ receptor activity. In the first experiment, intracerebroventricular infusion of letrozole, which prevents the synthesis of estradiol, blocked the ability of peripheral estradiol administration in ovariectomized rats to enhance hippocampus-dependent memory in a radial-maze task. In the second experiment, hippocampal infusion of antide, a long-lasting $\mathrm{GnRH}$ receptor antagonist, blocked the ability of peripheral estradiol administration in ovariectomized rats to enhance hippocampus-dependent memory. In the third experiment, hippocampal infusion of $\mathrm{GnRH}$ enhanced hippocampus-dependent memory, the effects of which were blocked by letrozole infusion. Results indicate that peripheral estradiol-induced enhancement of cognition is mediated by brain-derived estradiol via hippocampal GnRH receptor activity.
\end{abstract}

Key words: estradiol; estrogen; GnRH; hippocampus; memory

\section{Significance Statement}

Results of years of research have demonstrated that circulating estradiol, the main estrogen produced by the ovaries, impacts memory and the hippocampus. More recently, data have revealed that the brain can synthesize its own estradiol, the release of which also impacts the hippocampus. The relationship between the ability of circulating estradiol and brain-derived estradiol to impact the hippocampus and hippocampusdependent memory is unclear. Here we demonstrate that the impact of circulating estradiol on memory is mediated by brain-derived estradiol through mechanisms involving gonadotropin-releasing hormone $(\mathrm{GnRH})$. These data have significance for understanding mechanisms by which loss of ovarian hormones can impact memory.

\section{Introduction}

$17 \beta$-Estradiol (estradiol), the primary estrogen synthesized by the ovaries, impacts memory and the hippocampus (Luine, 2014). Specifically, systemic estradiol

Received October 23, 2016; accepted November 14, 2016; First published December 02, 2016.

The authors declare no competing financial interests. treatment to ovariectomized rats enhances performance on a variety of tasks designed to measure hippocampusdependent memory (Daniel and Bohacek, 2010; Boulware et al., 2012). The ability of circulating estradiol to enhance 
performance on hippocampus-dependent tasks is associated with structural changes in the hippocampus that are hypothesized to correlate with memory formation (Spencer et al., 2008). For example, ovariectomy decreases dendritic spine density in region CA1 in rat hippocampus, and systemic estradiol administration reverses these effects (Gould et al., 1990). Additionally, dendritic spine density fluctuates throughout the estrous cycle of rats, with higher levels of estradiol corresponding to greater hippocampal dendritic spine density (Woolley et al., 1990). Results of these early studies as well as many subsequent ones (Smith et al., 2009) implicate ovarian estrogens as mediators of hippocampal synaptic plasticity.

More recent work has called into question this traditional view, that estrogens derived from the periphery impact hippocampal synapse structure (see Fester and Rune, 2014). All proteins required for estradiol synthesis are located in the hippocampus, including aromatase, the enzyme responsible for the conversion of testosterone to estradiol (Furukawa et al., 1998; Fester et al., 2011; Tabatadze et al., 2014). Whereas application of physiological or supraphysiological levels of estradiol to hippocampal slices had no impact on dendritic spine density (Kretz et al., 2004), inhibition of hippocampal estradiol synthesis via aromatase inhibitors decreased dendritic spine density (Prange-Kiel et al., 2003) and synaptic protein expression (Prange-Kiel et al., 2006), suggesting that hippocampus-derived and not peripherally derived estradiol is critical in maintaining hippocampal synapses.

Data implicating a role for gonadotropin-releasing hormone $(\mathrm{GnRH})$ in hippocampal synaptic plasticity may reconcile conflicting evidence regarding impacts of peripheral versus brain-derived estradiol in the hippocampus. For instance, release of $\mathrm{GnRH}$ is regulated by peripheral estradiol (Terasawa and Kenealy, 2012), and the hippocampus expresses high levels of GnRH receptors on cells capable of estradiol synthesis (Fester et al., 2012). GnRH treatment in rat hippocampal slices induces long-lasting enhancement of synaptic transmission in CA1, effects of which are mediated by local estradiol synthesis, as application of an aromatase inhibitor blocks the effect (Wang et al., 2010; Schang et al., 2011). Furthermore, $\mathrm{GnRH}$ treatment dose-dependently stimulated estradiol synthesis in the hippocampus, thereby affecting dendritic spine density and levels of the synaptic proteins synaptophysin and spinophilin, effects of which were blocked by inhibiting estradiol synthesis (Fester et al., 2012; Prange-Kiel et al., 2013). Collectively, these results

This work was supported by grant R01AG041374 from the National Institute on Aging (JMD).

Britta S. Nelson's current affiliation is Dept. of Physiology and Pharmacology, College of Veterinary Medicine, The University of Georgia, Athens, GA 30602.

Correspondence should be addressed to Britta Nelson, Department of Physiology and Pharmacology, College of Veterinary Medicine, The University of Georgia, Athens, GA 30602. E-mail: britta5@uga.edu.

DOI:http://dx.doi.org/10.1523/ENEURO.0321-16.2016

Copyright @ 2016 Nelson et al.

This is an open-access article distributed under the terms of the Creative Commons Attribution 4.0 International, which permits unrestricted use, distribution and reproduction in any medium provided that the original work is properly attributed. indicate that $\mathrm{GnRH}$ regulates hippocampal neuroestradiol synthesis, which in turn affects hippocampal morphology. The subsequent effect of these neural changes on memory has not been examined.

The goal of the current experiments was to test the hypothesis that circulating estradiol impacts hippocampusdependent memory through regulation of hippocampusderived estradiol via mechanisms involving GnRH. In an initial experiment, we inhibited brain estradiol synthesis via administration of an aromatase inhibitor to ovariectomized rats that were treated systemically with estradiol to determine whether brain estradiol is necessary for circulating estradiol to enhance memory. Next, we administered a $\mathrm{GnRH}$ receptor antagonist to the dorsal hippocampus of ovariectomized estradiol-treated rats to determine whether hippocampus GnRH receptor activation is necessary for circulating estradiol to enhance memory. Finally, we determined whether a relationship exists between effects of $\mathrm{GnRH}$ and neuroestradiol on hippocampus-dependent memory. We administered GnRH or GnRH plus an aromatase inhibitor into the dorsal hippocampus of ovariectomized rats to establish, first, whether $\mathrm{GnRH}$ receptor activation in the absence of circulating estradiol is sufficient to enhance memory and, second, whether $\mathrm{GnRH}$ effects are dependent on neuroestradiol synthesis.

\section{Materials and Methods}

\section{Subjects and hormone treatments}

Female Long-Evans hooded rats, approximately 2 months of age, were purchased from Harlan Sprague Dawley (Indianapolis, IN). Animal care was in accordance with guidelines set by the National Institutes of Health Guide for the Care and Use of Laboratory Animals, and all procedures were approved by the Institutional Animal Care and Use Committee of Tulane University. Rats were housed individually in a temperature-controlled vivarium under a 12-h light/dark cycle (lights on at 7:00 a.m.). One week after arrival, all rats were ovariectomized while under anesthesia induced by injections of ketamine (100 $\mathrm{mg} / \mathrm{kg}$ i.p., Bristol Laboratories, Syracuse, NY) and xylazine (7 mg/kg i.p., Miles Laboratories, Shawnee, KS). At the time of surgery, animals were implanted with $5 \mathrm{~mm}$ Silastic brand capsules (0.058-inch i.d. and 0.077-inch o.d., Dow Corning, Midland, MI) containing either $25 \%$ $17 \beta$-estradiol (Sigma-Aldrich, St. Louis, MO) diluted with cholesterol or $100 \%$ cholesterol vehicle. We have reported previously that estradiol implants of these dimensions maintain blood plasma estradiol levels of 26-47 $\mathrm{pg} / \mathrm{ml}$, which fall within the physiological range of cycling female rats (Bohacek and Daniel, 2007, 2010) . See Fig. 1 for experimental timeline.

\section{Maze training: acquisition}

One week after ovariectomy, rats were placed on diets to maintain body weights at $85-90 \%$ of presurgery weights and were trained to obtain food rewards (Froot Loops; Kellogg Co., Battle Creek, MI) from the arms of an elevated eight-arm radial maze purchased from Lafayette Instrument Co. (Lafayette, IN). The maze consists of black metal floors and clear acrylic walls with arms $(10 \mathrm{~cm}$ wide 


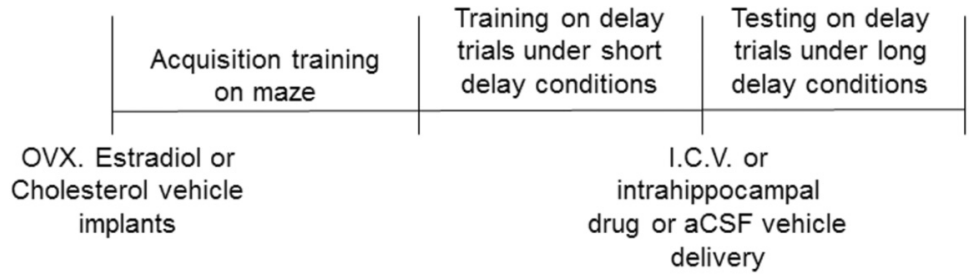

Figure 1. Experimental timeline used in all experiments. OVX, ovariectomy.

$\times 70 \mathrm{~cm}$ long $\times 20 \mathrm{~cm}$ high) extending out from an octagonal center ( $33 \mathrm{~cm}$ across). The maze is located in the center of a $3 \times 5 \mathrm{~m}$ room and raised $\sim 1 \mathrm{~m}$ from the floor. Several extramaze cues, including overhead fluorescent lights, desk, chairs, sink, and door, were visible from the maze. To begin a trial, a rat was placed in the center compartment in a pseudorandom orientation and had access to all eight arms. Arm choices were recorded by an observer seated in a fixed location approximately $1 \mathrm{~m}$ away from the maze. An arm choice was scored if the rat traversed half the length of an arm. Rats were allowed to choose arms in any order until all arms had been visited or $5 \mathrm{~min}$ had elapsed. Errors were reentries into previously visited arms. Each animal received one trial per day across 24 days of acquisition.

\section{Maze training: short delays}

After acquisition training was completed, rats were trained on delay trials under short delay conditions to acclimate them to delay trial procedures that would later be used to test treatment effects. For delay trials, an animal was removed from the maze after the fourth correct arm choice and put in a holding cage for delays of 1 or $30 \mathrm{~min}$, after which it was returned to the maze until the four remaining, still baited arms, were visited or until $5 \mathrm{~min}$ had elapsed. Consequently, animals had to remember over an extended period of time which arms had already been entered. Arm choice accuracy was measured by the number of errors of the first eight arm choices. Rats were given one day of habituation to a 1-min delay trial. Subsequently, two trials (one per day) were conducted for each delay beginning with a 1-min delay.

\section{Drug treatments}

After completing short-delay trials on the radial maze, drug treatments began. Drugs or vehicle were delivered to the lateral ventricle or the dorsal hippocampus as described below. Rats were anesthetized with ketamine and xylazine and placed in a stereotaxic frame.

\section{Experiment 1: Letrozole}

A hole was drilled in the skull, and cannulae (Brain Infusion Kits, Alzet, Cupertino, CA) were lowered through the hole to the appropriate depth (to the left lateral ventricle located $-0.3 \mathrm{~mm} \mathrm{AP},-1.2 \mathrm{~mm} \mathrm{ML}$, and $-4.5 \mathrm{~mm} \mathrm{DV}$ ) and anchored to the skull with screws and dental acrylic. Cannulae were connected to Alzet osmotic minipumps by vinyl tubing that delivered artificial cerebrospinal fluid (aCSF) vehicle (Tocris Bioscience, Ellisville, $\mathrm{MO}$ ) or letrozole $(1.67 \mu \mathrm{g} / \mu \mathrm{l}$; Bachem, Torrance, CA), an aromatase inhibitor, dissolved in dimethylsulfoxide and diluted in vehicle at a rate of $0.5 \mu \mathrm{l} / \mathrm{h}$. All pumps were implanted s.c. in the nape of the neck, and cannulae were inserted after the pumps began pumping. Cholesterol-treated rats received osmotic minipumps containing letrozole ( $\mathrm{CH}$ letrozole, $n=10)$, or vehicle aCSF (CH aCSF, $n=14$ ). Estradiol-treated rats received osmotic minipumps containing letrozole (E letrozole, $n=12$ ) or vehicle aCSF ( $E+$ aCSF, $n=13$ ). To facilitate procedures, surgeries, and subsequent behavior testing were staggered across four cohorts. All groups were represented in all cohorts.

\section{Experiment 2: Antide}

Holes were drilled in the skull, and a 10- $\mu$ l Hamilton syringe was lowered through each hole to the appropriate depth to the left and right dorsal hippocampus $(-3.3 \mathrm{~mm}$ AP, $\pm 1.5 \mathrm{~mm} \mathrm{ML}$, and $-2.0 \mathrm{~mm} \mathrm{DV}$ ). The long-lasting $\mathrm{GnRH}$ receptor antagonist, antide, diluted in aCSF (1 $\mu \mathrm{g} / \mu \mathrm{l}$; Sigma-Aldrich) was infused bilaterally via syringe at a rate of $1 \mu \mathrm{l} / \mathrm{min}$ over a period of $2.5 \mathrm{~min}$. Syringes remained in place for an additional minute to ensure diffusion of the drug. The dose of antide was based on a report indicating a single hypothalamic infusion of antide blocked estrous cycles in rats, an effect that persisted from 11 days to $>4$ months, indicating its long-term effectiveness (Weesner and Pfaff, 1994). Half of the cholesterol-treated rats received antide infusions $(\mathrm{CH}$ Antide, $n=10$ ), and half received vehicle aCSF (CH aCSF, $n$ $=10$ ). Half of the estradiol-treated rats received antide infusions ( $E$ Antide, $n=10$ ) and half received vehicle aCSF (E aCSF, $n=10$ ). To facilitate procedures, surgeries, and subsequent behavior testing were staggered across two cohorts. All groups were represented in both cohorts. One rat (CH Antide) died prior to data collection due to surgical complications.

To confirm that potential effects of intrahippocampal antide infusions were due to impacts in the hippocampus and generalized effects via spread of the drug to ventricles, we infused antide following identical procedures as described above to the hippocampus of two gonadally intact female rats. Analyses of daily vaginal smears collected by lavage beginning 1 week after the antide infusions revealed that both rats continued to display regular 4-d estrous cycles. These results provided evidence that intrahippocampal administered antide was not reaching the hypothalamus, where it would disrupt the estrous cycle of the rat, suggesting that our regimen of antide administration did not result in spread of drug to the ventricles.

\section{Experiment 3: GnRH and GnRH + letrozole}

Holes were drilled in the skull, and cannulae (Brain Infusion Kits, Alzet) were lowered through the holes to the 
appropriate depth (to the left and right dorsal hippocampi, $-3.3 \mathrm{~mm} \mathrm{AP}, \pm 1.5 \mathrm{~mm} \mathrm{ML}$, and $-2.0 \mathrm{~mm} \mathrm{DV}$ ) and anchored to the skull with screws and dental acrylic. Cannulae were connected to Alzet osmotic minipumps by vinyl tubing that delivered artificial aCSF vehicle $(n=8)$, $\mathrm{GnRH}(16.6 \mathrm{ng} / \mathrm{h}$; Sigma-Aldrich; $n=9)$ or $\mathrm{GnRH}+$ letrozole $(31.5 \mathrm{ng} / \mathrm{h})$ diluted in vehicle delivered at a rate of $0.25 \mu \mathrm{l} / \mathrm{h}(n=9)$. All pumps were implanted s.c. in the nape of the neck, and cannulae were inserted after the pumps began pumping. To facilitate procedures, surgeries, behavior testing, and sacrifice were staggered across two cohorts. All groups were represented in both cohorts.

\section{Behavioral testing: long-delay trials}

One week after initiation of drug treatments, behavioral testing began. Behavioral testing consisted of long-delay trials during which delays of 2 and $4 \mathrm{~h}$ were imposed between the fourth and fifth arm choices. Two trials were conducted for each delay using procedures identical to those used for the short-delay trials previously described. We chose to assess effects of drug treatments only under the two long-delay conditions and not during shorter delays because of time constraints related to use of brain infusion kits and because previous work by us (Daniel et al., 2005) and others (Bimonte and Denenberg, 1999) indicated that effects of estradiol on memory are most apparent under conditions of high memory demand.

\section{Hormone treatment efficacy}

At the time the rats were killed, uteri were extracted and $1-\mathrm{cm}$-long sections of the right uterine horns (cut at the base) were weighed to verify efficacy of hormone treatment. Additionally, proper removal of the ovaries and integrity of the implanted capsules were assessed.

\section{Statistical analyses}

Arm-choice accuracy data from short-delay trials were analyzed by two-way ANOVA (hormone $x$ delay) with repeated measures on delay for Experiments 1 and 2 and one-way repeated measures ANOVA (delay) for Experiment 3. Arm-choice accuracy data from long-delay trials in Experiments 1 and 2 were analyzed by three-way ANOVA (hormone $\times$ drug $\times$ delay) with repeated measures on delay. Post hoc tests [Fisher's least significant difference (LSD), $p<0.05$ ] were used to probe group differences following significant interactions of hormone $x$ drug. Arm-choice accuracy data from long-delay trials in Experiment 3 were analyzed by two-way ANOVA (drug $X$ delay) with repeated measures on delay. Fisher's LSD post hoc tests were used to probe group differences following a main effect of drug. A one-way ANOVA, with hormone group as the factor, was used to test for differences in uterine weight in Experiments 1 and 2.

\section{Results}

\section{Experiment 1}

The goal of the first experiment was to test the hypothesis that the ability of circulating estradiol to impact hippocampus-dependent memory was dependent on neuroestradiol. Thus, we determined whether central delivery of the aromatase inhibitor letrozole would block effects of pe- ripherally administered estradiol to ovariectomized rats on radial-maze performance. Rats were ovariectomized and received subcutaneous estradiol or cholesterol vehicle capsule implants. After training on short-delay trials in the radialmaze, rats received chronic intracerebroventricular (i.c.v.) delivery of vehicle or letrozole via cannulae connected to osmotic minipumps. Rats then were tested on long-delay trials on the radial-arm maze.

\section{Short-delay trials (before drug treatment)}

Analyses of arm-choice accuracy data from training on the two short-delay trials indicated a main effect of delay $\left(F_{(1,47)}=33.88, p=0.0001\right)$ indicating an increased numbers of errors on the longer delay (Fig. 2). There was no effect of hormone or an interactive effect of hormone by delay, indicating that estradiol treatment did not affect performance during short-delay trials.

\section{Long-delay trails (during drug treatment)}

As illustrated in Fig. 3, chronic i.c.v. administration of letrozole blocked an estradiol-induced enhancement in memory as assessed on a radial-arm maze during testing across long-delay trials when delays of 2 and $4 \mathrm{~h}$ were imposed between the fourth and fifth arm choices. There was a significant main effect of hormone $\left(F_{(1,45)}=5.94, p\right.$ $=0.019$ ) on maze performance as measured by number of errors. There was also a significant interactive effect of hormone $\times \operatorname{drug}\left(F_{(1,45)}=4.22, p=0.046\right)$, indicating that the effect of estradiol treatment differed depending on whether letrozole was administered. Post hoc analyses revealed that rats that received estradiol treatment and control i.c.v. aCSF infusion (E aCSF) had significantly better arm choice accuracy (fewer errors) than rats that received cholesterol control treatment and aCSF or letrozole infusion ( $\mathrm{CH}$ aCSF, $\mathrm{CH}$ Letrozole) as well as rats that received estradiol treatment and letrozole infusion $(E$ Letrozole). There were no main effects of drug or delay.

\section{Hormone treatment efficacy}

There was a significant difference between groups in uterine weight $\left(F_{(1,47)}=504.82, p<0.001\right)$, indicating that hormone treatments were effective. Estradiol-treated rats had larger uteri (mean \pm SEM; $68.9 \pm 3.04 \mathrm{mg}$ ) than cholesterol-treated rats $(18.7 \pm 3.27 \mathrm{mg})$.

\section{Experiment 2}

Results of our first experiment revealed that synthesis of neuroestradiol was a necessary component in the ability of circulating estradiol to enhance memory. We hypothesized that $\mathrm{GnRH}$, which is regulated by circulating estradiol and can impact levels of neuroestradiol (Terasawa and Kenealy, 2012), is involved in the enhancement. Thus, to explore the importance of GnRH in the effects of circulating estradiol on memory, we assessed the ability of antagonizing $\mathrm{GnRH}$ receptors in the hippocampus to block the impact of circulating estradiol on memory. Rats were ovariectomized and received subcutaneous estradiol or cholesterol vehicle capsule implants. After training on short-delay trails in the radial maze, rats received a single bilateral infusion of vehicle or antide, a long-lasting $\mathrm{GnRH}$ receptor antagonist, to the dorsal hippocampus. Rats then were tested on long-delay trials in the maze. 


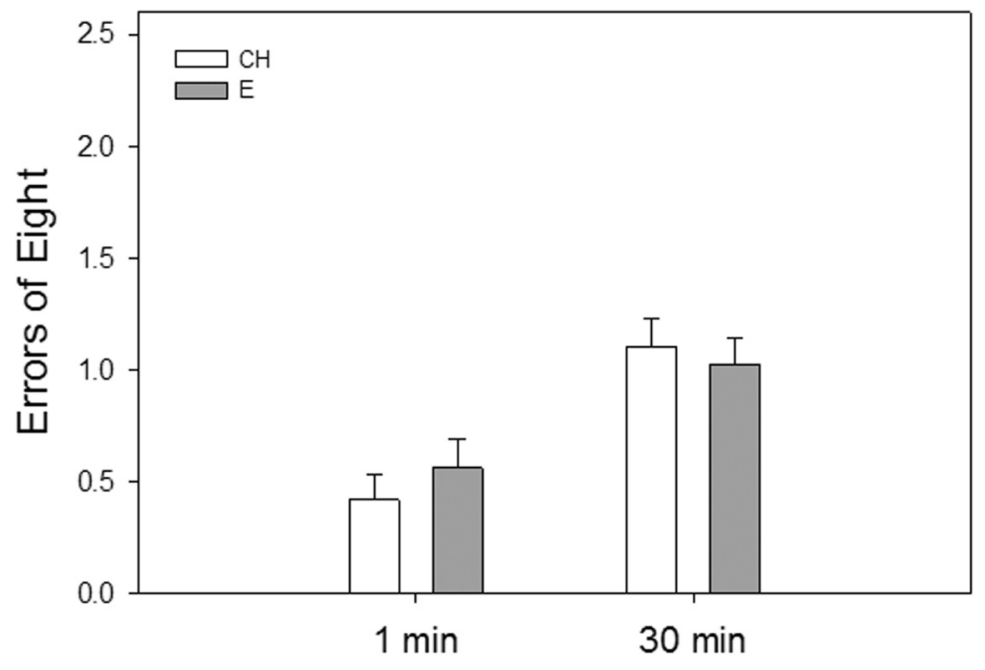

Delay

Figure 2. Working memory performance of ovariectomized estradiol-treated $(\mathrm{E})$ and cholesterol vehicle-treated $(\mathrm{CH})$ ovariectomized rats in a radial-arm maze during training on short-delay trials in Experiment 1. Delays were imposed between the fourth and fifth arm choices. Mean number of errors of the first eight arm choices ( \pm SEM) at each delay. $* p<0.05$ vs. 1-min delay.

\section{Short-delay trials (before drug treatment)}

Analyses of arm-choice accuracy data from training on the two short-delay trials showed a main effect of delay $\left(F_{(1,37)}=8.45, p=0.006\right)$, indicating an increased numbers of errors on the longer delay. There was no effect of hormone or an interactive effect of hormone by delay, indicating that estradiol treatment did not affect performance during short-delay trials.

\section{Long-delay trails (after drug treatment)}

As illustrated in Fig. 4, intrahippocampal infusion of antide, a long-lasting $\mathrm{GnRH}$ receptor antagonist, blocked an estradiol-induced enhancement in memory as assessed on a radial-arm maze during testing across long-delay trials. Data from two rats ( $\mathrm{CH}$ antide, $\mathrm{E}$ antide) were excluded from the long-delay data analyses because they did not complete either testing trial on the 4-h delay. There were significant main effects of hormone $\left(F_{(1,33)}=5.47, p=0.025\right)$, and drug $\left(F_{(1,33)}=6.59, p=0.015\right)$ on maze performance as measured by number of errors. There was also a significant interactive effect of hormone $\times$ drug $\left(F_{(1,33)}=5.07, p=\right.$ 0.031 ), indicating that the effect of estradiol treatment differed depending on whether antide was administered. Post hoc analyses revealed that the rats that received estradiol treatment and control aCSF infusion (E aCSF) had significantly better arm choice accuracy (fewer errors) than rats that received cholesterol control treatment and aCSF or antide infusion ( $\mathrm{CH}$ aCSF, $\mathrm{CH}$ antide) as well as rats that received estradiol treatment and antide infusion ( $E$ antide). There were no effects of delay.

\section{Hormone treatment efficacy}

There was a significant difference between groups in uterine weight $\left(F_{(1,35)}=310.94, p<0.001\right)$, indicating that hormone treatments were effective. Estradiol-treated rats had larger uteri (mean \pm SEM; $69.8 \pm 1.12 \mathrm{mg}$ ) than cholesterol-treated rats $(12.8 \pm 2.97 \mathrm{mg})$.

\section{Experiment 3}

Results of Experiments 1 and 2 demonstrated that neuroestradiol synthesis and action at hippocampal $\mathrm{GnRH}$ receptors are each necessary for circulating estradiol to impact memory. In Experiment 3, we investigated whether there was an association between these two effects. Specifically, we determined whether GnRH delivered to the hippocampus in the absence of circulating estradiol was sufficient to enhance memory and whether effects of GnRH on memory were dependent on neuroestradiol synthesis. Rats were ovariectomized, and all received subcutaneous cholesterol vehicle capsule implants. After training on short-delay trials in the radial-arm maze, rats received chronic intrahippocampal delivery of vehicle, GnRH, or GnRH + letrozole via cannulae connected to osmotic minipumps. Rats then were tested on long-delay trials in the maze.

\section{Short-delay trials (before drug treatment)}

Analyses of arm-choice accuracy data from training on the two short-delay trials revealed no effect of delay indicating that the increase in delay did not significantly impact performance in ovariectomized cholesterol vehicle-treated rats.

\section{Long-delay trails (during drug treatment)}

As illustrated in Fig. 5, results indicate that hippocampal GnRH exerts cognitive benefits that are dependent on hippocampal estradiol synthesis. Analyses revealed a significant main effect of treatment group $\left(F_{(1,23)}=3.81, p=\right.$ 0.037 ) on maze performance as measured by number of errors. Post hoc analyses revealed that the rats that received GnRH infusion had significantly better arm choice accuracy (fewer errors) than rats that received aCSF control infusion or $\mathrm{GnRH}+$ letrozole infusion. There were no effects of delay.

\section{Hormone treatment efficacy}

Atrophy of uteri of all animals was confirmed at the time of euthanasia. 


\section{A}

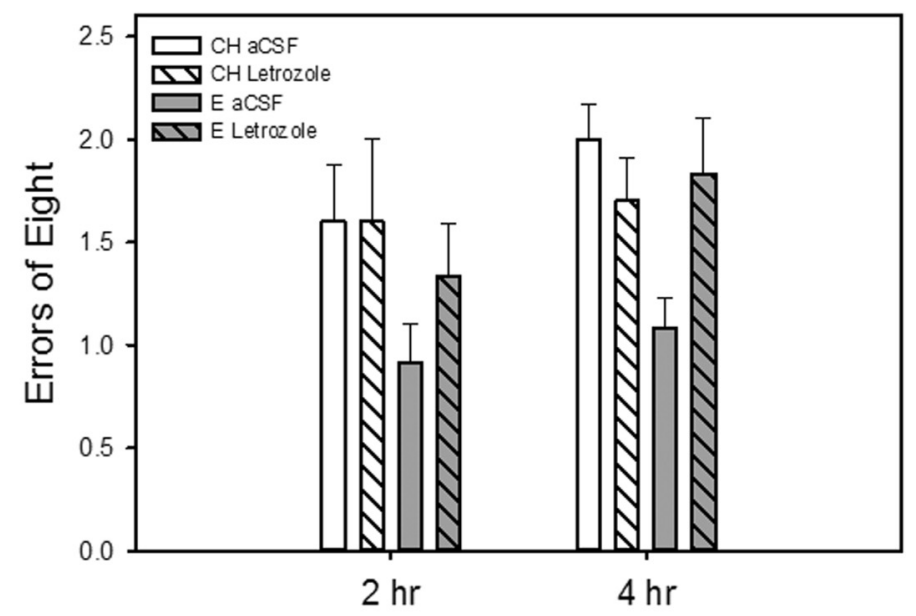

B

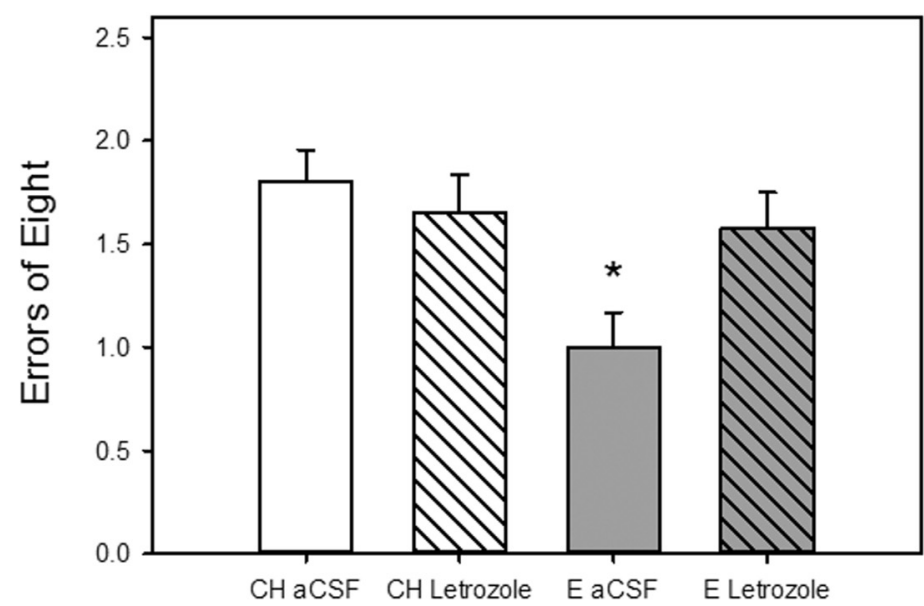

Figure 3. Effects of estradiol treatment and inhibition of brain estradiol synthesis on a hippocampus-dependent spatial memory task. Rats were ovariectomized and implanted with capsules containing estradiol $(\mathrm{E})$ or cholesterol vehicle $(\mathrm{CH})$. $\mathrm{Chronic}$ intracerebroventricular delivery of the aromatase inhibitor letrozole or aCSF vehicle was initiated 1 week before and maintained throughout testing. $\boldsymbol{A}$, Working memory performance in a radial-arm maze with delays imposed between the fourth and fifth arm choices. Mean number of errors of the first eight arm choices $( \pm S E M)$ at each delay. $\boldsymbol{B}$, Mean number of errors of the first eight arm choices $( \pm$ SEM) averaged across both delays. $* p<0.05$ vs. all other groups.

\section{Discussion}

Results of the present experiments indicate that the positive impact on spatial memory of chronic systemic estradiol treatment in ovariectomized rats is mediated by brain-derived estradiol. Further, the current data provide evidence that the relationship between the effects of circulating estrogens and brain estrogens on memory is mediated by $\mathrm{GnRH}$. Specifically, we showed that blocking brain-derived estradiol synthesis via letrozole, an aromatase inhibitor, blocked the ability of systemic estradiol treatment to ovariectomized rats to enhance performance on a spatial radial-arm maze task. Antagonizing hippocampal GnRH receptors also blocked the estradiolinduced effects on performance, demonstrating that hippocampal $\mathrm{GnRH}$ receptor signaling is required for peripheral estradiol treatment to enhance memory. Furthermore, hippocampal GnRH treatment enhanced memory in ovariectomized rats in the absence of peripherally administered estrogens. This enhancement in memory was blocked by letrozole, indicating that $\mathrm{GnRH}$ is exerting benefits on memory by impacting neuroestradiol synthesis in the hippocampus. Collectively, our data provide support for the hypothesis that circulating estrogens impact cognition by acting to mediate brain levels of $\mathrm{GnRH}$, which in turn acts at receptors in the hippocampus to facilitate synthesis of neuroestradiol, which then impacts hippocampus-dependent memory.

The current data are consistent with previous work indicating that chronic systemic administration of estradiol to ovariectomized rats enhances spatial memory, an effect that is particularly evident as memory load increases (Bimonte and Denenberg, 1999; Daniel et al., 2005). In Experiments 1 and 2, estradiol compared with vehicle treatment enhanced performance on an eight-arm 


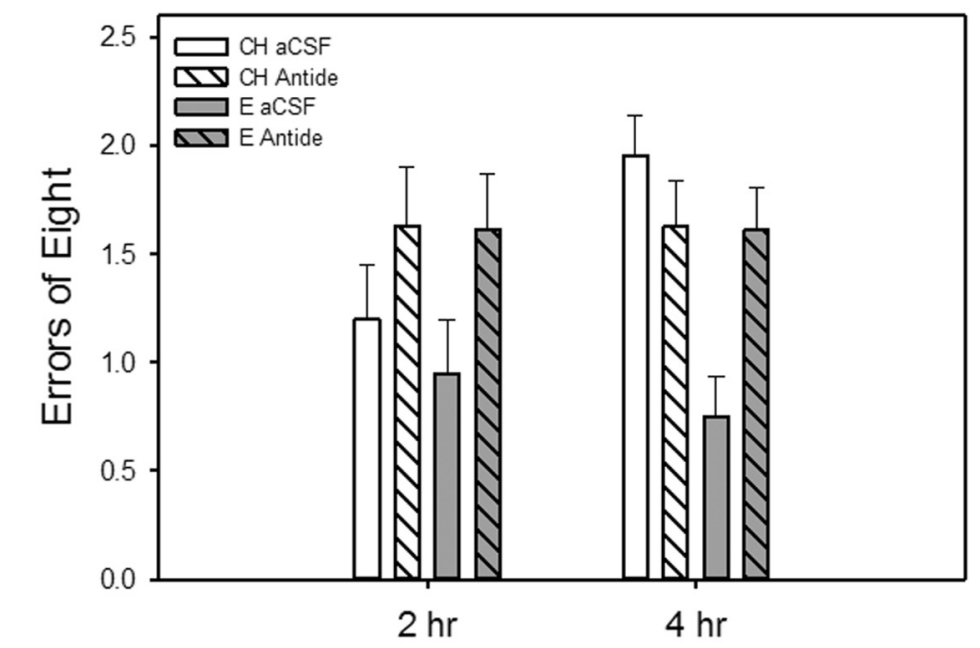

B

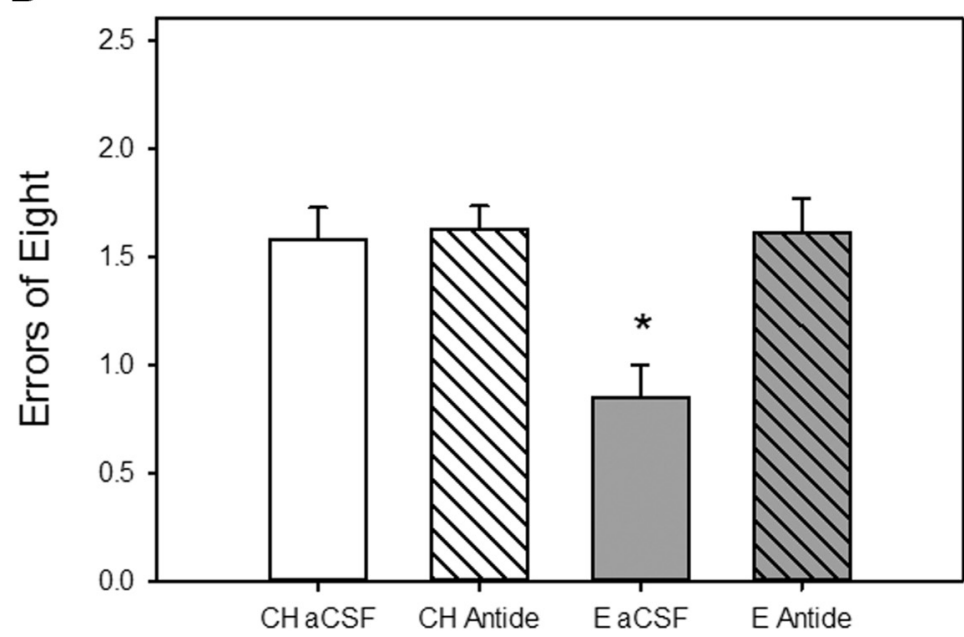

Figure 4. Effects of estradiol treatment and antagonism of hippocampal GnRH receptors on a hippocampus-dependent spatial memory task. Rats were ovariectomized and implanted with capsules containing estradiol $(\mathrm{E})$ or cholesterol vehicle $(\mathrm{CH})$. A single bilateral infusion of the long-lasting $\mathrm{GnRH}$ receptor antagonist antide or aCSF vehicle was delivered to the hippocampus 1 week before the initiation of testing. $\boldsymbol{A}$, Working memory performance in a radial-arm maze with delays imposed between the fourth and fifth arm choices. Mean number of errors of the first eight arm choices ( \pm SEM) at each delay. $\boldsymbol{B}$, Mean number of errors of the first eight arm choices $( \pm$ SEM) averaged across both delays. $* p<0.05$ vs. all other groups.

radial-maze task when long delays (i.e., 2 and 4 h) were imposed between the fourth and fifth arm choices. Results of Experiment 1 revealed that chronic systemic estradiol treatment acts via regulation of brain estradiol to exert its impact on memory, as inhibition of brain estradiol synthesis via central administration of letrozole blocked the effect. Importantly, the negative impact on memory of blocking brain estradiol was specific to rats receiving exogenous administration of estradiol. Letrozole administration had no effect on cognitive performance in ovariectomized controls, suggesting that brain estrogens do not impact hippocampus-dependent memory in the absence of circulating estrogens. In the present study, rats had been ovariectomized $\sim 2$ months before letrozole delivery. It remains to be determined whether neuroestradiol inhi- bition would impact memory after shorter periods of circulating estradiol deprivation.

The present data indicate that peripheral estradiol administration exerts effects on memory by regulating neuroestradiol synthesis. Supportive of the results are reports that levels of estradiol are present in higher concentrations in the hippocampus than in the periphery (Hojo et al., 2009) and are associated with levels of circulating estrogens (Fester et al., 2012). We hypothesize that the impact of neuroestradiol on memory is due to specific actions in the hippocampus. But because we delivered letrozole to the lateral ventricle, we cannot rule out the possibility that brain-derived estrogens synthesized elsewhere in the brain contributed to our observed effects. For example, neuroestradiol synthesized in the hypothalamus is critical 


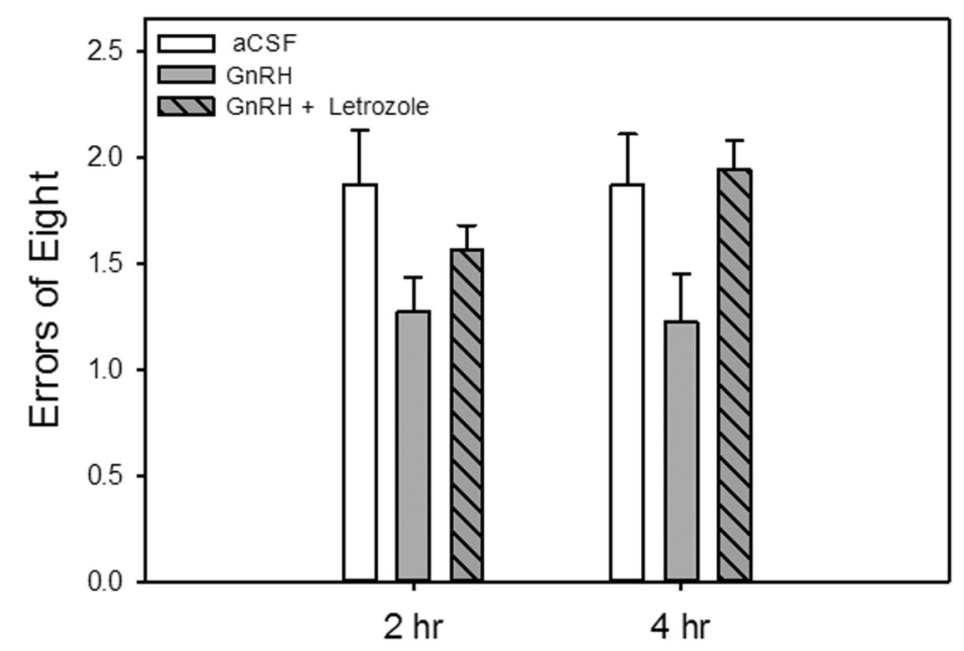

B

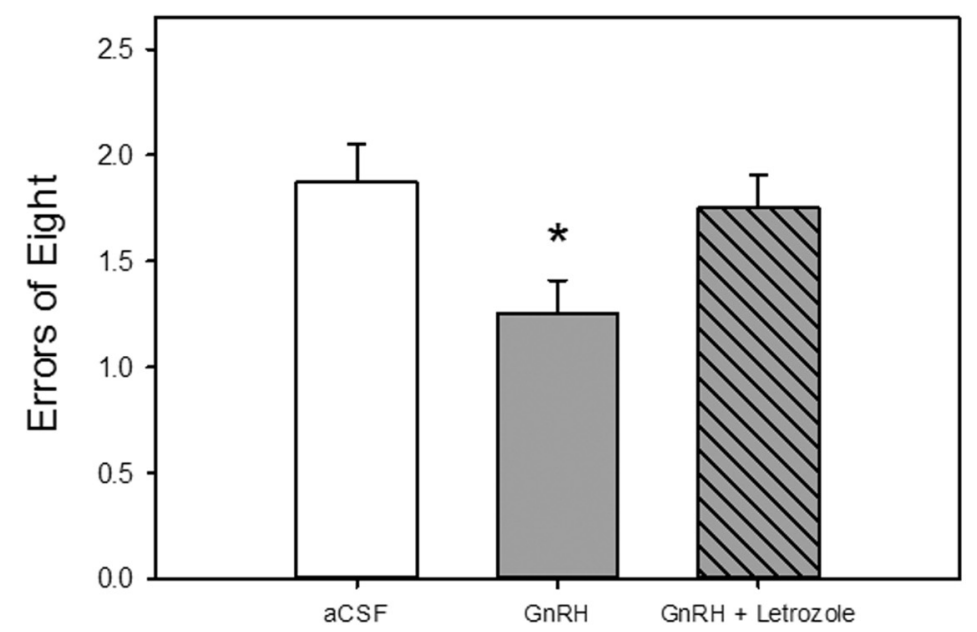

Figure 5. Effects of intrahippocampal delivery of GnRH alone or with an aromatase inhibitor on performance on a hippocampusdependent spatial memory task. Rats were ovariectomized, and all were implanted with capsules containing cholesterol vehicle. Chronic bilateral intrahippocampal delivery of $\mathrm{GnRH}, \mathrm{GnRH}+$ the aromatase inhibitor letrozole, or aCSF vehicle was initiated 1 week before and maintained throughout testing. $\boldsymbol{A}$, Memory performance in a radial-arm maze with delays imposed between the fourth and fifth arm choices. Mean number of errors of the first eight arm choices ( \pm SEM) at each delay. $\boldsymbol{B}$, Mean number of errors of the first eight arm choices ( \pm SEM) averaged across both delays. $* p<0.05$ vs. other groups.

in mediating the effects of peripheral estradiol on $\mathrm{GnRH}$ release in female primates (Kenealy et al., 2013), which could potentially reach the hippocampus to exert effects. Nevertheless, our data demonstrate that effects of exogenously administered circulating estradiol on cognition are mediated by brain-derived estrogens.

Our results are in contrast to results recently reported in which acute inhibition of hippocampal synthesis of estrogens via letrozole administration to ovariectomized mice impaired object memory consolidation and had no impact on the ability of i.c.v. administration of estradiol to enhance memory consolidation (Tuscher et al., 2016). In addition to differences in tasks and memory processes assessed, there are differences in treatment paradigms that may have contributed to these discrepant results. We administered letrozole chronically and to the lateral ventricles, whereas Tuscher et al. administered a single infusion to the hippocampus. Additionally, it is likely that the weeks of chronic circulating estradiol treatment in the current work would have a different impact on the brain and on hippocampus-derived estrogens than a single i.c.v. infusion of estradiol used in the previous report.

In the current work, results of Experiment 2 revealed that intrahippocampal delivery of antide, a GnRH receptor antagonist, blocked the ability of systemically administered estradiol to ovariectomized rats to impact performance on a hippocampus-dependent task. In parallel to results of letrozole treatment in Experiment 1, the impact 
of antide was specific to estradiol-treated females. These results support a specific role for $\mathrm{GnRH}$ actions in the hippocampus in the mediation of circulating estradiolinduced effects on memory. The current data support previous work on the effects of $\mathrm{GnRH}$ on learning and memory whereby both peripheral and central administration of GnRH to aged male and female mice increased neurogenesis throughout the brain as well as enhanced hippocampus-dependent memory (Zhang et al., 2013).

Circulating estrogens regulate $\mathrm{GnRH}$ release through both positive and negative feedback mechanisms. In normally cycling female rats, estradiol exerts negative feedback on GnRH release during the early follicular phase of the estrous cycle (Clarke and Cummins, 1987) by acting at the level of the arcuate nucleus in the hypothalamus, interacting with kisspeptin neurons which synapse directly on GnRH neurons (Smith et al., 2005; Roa et al., 2008). As estradiol levels rise, they act to increase release of $\mathrm{GnRH}$ via positive feedback mechanisms that correspond to ovulation. This surge of $\mathrm{GnRH}$ is due to indirect actions of estradiol on kisspeptin neurons in the anteroventral periventricular (AVPV) nucleus of the hypothalamus (Roa et al., 2009). In the current experiments, rats were ovariectomized and administered constant estradiol at physiological levels. As such, the feedback mechanisms on $\mathrm{GnRH}$ neurons differ from those of normally cycling gonadally intact rodents. In gonadectomized rodents, continuous estradiol treatment exerts both negative and positive feedback on a daily basis rather than over a more extended period across the 4-d estrous cycle (Legan and Karsch, 1975). As such, rats continuously treated with estradiol would likely experience an increased level of $\mathrm{GnRH}$ receptor activation compared with normally cycling rodents.

Although our data point to actions of $\mathrm{GnRH}$ in the hippocampus, the potential source of GnRH to the hippocampus is unclear. The possibility of direct projections between the hypothalamus and hippocampus is still under debate (Colom et al., 2005; Prange-Kiel et al., 2013), although early work has found $\mathrm{GnRH}$-immunopositive processes to the hippocampus in female rats (Merchenthaler et al., 1984). Additionally, $\mathrm{GnRH}$ is present in cerebral spinal fluid, indicating that it can have widespread effects throughout the brain via diffusion through the ventricles (Skinner and Caraty, 2002). In the present studies, $\mathrm{GnRH}$ is proposed to impact memory by acting in the hippocampus to regulate neuroestradiol synthesis. A possible mechanism by which GnRH regulates neuroestradiol synthesis is through increasing levels of steroid acute regulatory protein (StAR), which initiates neurosteroid synthesis (Rosati et al., 2011). Further, GnRH is able to directly stimulate estradiol synthesis in ovarian granulosa cells (Janssens et al., 2000), and activation of GnRH receptors increases estradiol synthesis in the hippocampus, impacting dendritic spine density and levels of synaptic proteins (Fester et al., 2012; Prange-Kiel et al., 2013). Results of Experiment 3 in the present work, in which a $\mathrm{GnRH}$-induced enhancement in hippocampusdependent memory was blocked by inhibition of estradiol synthesis in the hippocampus, provide a functional implication for behavior of these neural effects.

In conclusion, results of the current study offer evidence to reconcile the conflicting data regarding the roles of circulating and hippocampus-derived estrogens on memory. They indicate that circulating estrogens impact memory through their ability to regulate hippocampal neuroestradiol synthesis. They also suggest that the negative impact of long-term ovarian hormone deprivation on memory is due to decreased levels of hippocampusderived estrogens that would result from decreased levels of circulating estrogens. Future research should aim to further elucidate the relationship between circulating estradiol, the hypothalamus, and subsequent effects on the hippocampus, cognition, and other behavioral measures.

\section{References}

Bimonte HA, Denenberg VH (1999) Estradiol facilitates performance as working memory load increases. Psychoneuroendocrinology 24:161-173. Medline

Bohacek J, Daniel JM (2007) Increased daily handling of ovariectomized rats enhances performance on a radial-maze task and obscures effects of estradiol replacement. Horm Behav 52:237243. CrossRef Medline

Bohacek J, Daniel JM (2010) The beneficial effects of estradiol on attentional processes are dependent on timing of treatment initiation following ovariectomy in middle-aged rats. Psychoneuroendocrinology 35:694-705. CrossRef Medline

Boulware MI, Kent BA, Frick KM (2012) The impact of age-related ovarian hormone loss on cognitive and neural function. Curr Top Behav Neurosci 10:165-184. CrossRef Medline

Clarke IJ, Cummins JT (1987) Pulsatility of reproductive hormones: physiological basis and clinical implications. Baillières Clin Endocrinol Metab 1:1-21. CrossRef

Colom LV, Castaneda MT, Reyna T, Hernandez S, Garrido-Sanabria E (2005) Characterization of medial septal glutamatergic neurons and their projection to the hippocampus. Synapse 58:151-164. CrossRef Medline

Daniel JM, Bohacek J (2010) The critical period hypothesis of estrogen effects on cognition: insights from basic research. Biochim Biophys Acta 1800:1068-1076. CrossRef Medline

Daniel JM, Hulst JL, Lee CD (2005) Role of hippocampal M2 muscarinic receptors in the estrogen-induced enhancement of working memory. Neuroscience 132:57-64. CrossRef Medline

Fester L, Prange-Kiel J, Jarry H, Rune GM (2011) Estrogen synthesis in the hippocampus. Cell Tissue Res 345:285-294. CrossRef Medline

Fester L, Prange-Kiel J, Zhou L, Blittersdorf BV, Böhm J, Jarry H, Schumacher M, Rune GM (2012) Estrogen-regulated synaptogenesis in the hippocampus: sexual dimorphism in vivo but not in vitro. J Steroid Biochem Mol Biol 131:24-29. CrossRef

Fester L, Rune GM (2014) Sexual neurosteroids and synaptic plasticity in the hippocampus. Brain Res 1621:162-169.

Furukawa A, Miyatake A, Ohnishi T, Ichikawa Y (1998) Steroidogenic acute regulatory protein (StAR) transcripts constitutively expressed in the adult rat central nervous system: colocalization of StAR, cytochrome P-450SCC (CYP XIA1), and 3betahydroxysteroid dehydrogenase in the rat brain. $\mathrm{J}$ Neurochem 71 : 2231-2238. CrossRef

Gould E, Woolley CS, Frankfurt M, McEwen BS (1990) Gonadal steroids regulate dendritic spine density in hippocampal pyramidal cells in adulthood. J Neurosci 10:1286-1291. Medline

Hojo Y, Higo S, Ishii H, Ooishi Y, Mukai H, Murakami G, Kominami T, Kimoto T, Honma S, Poirier D, Kawato S (2009) Comparison between hippocampus-synthesized and circulation-derived sex steroids in the hippocampus. Endocrinology 150:5106-5112. CrossRef Medline 
Janssens RM, Brus L, Cahill DJ, Huirne JA, Schoemaker J, Lambalk CB (2000) Direct ovarian effects and safety aspects of $\mathrm{GnRH}$ agonists and antagonists. Hum Reprod Update 6:505-518. Medline

Kenealy BP, Kapoor A, Guerriero KA, Keen KL, Garcia JP, Kurian JR, Ziegler TE, Terasawa E (2013) Neuroestradiol in the hypothalamus contributes to the regulation of gonadotropin releasing hormone release. J Neurosci 33:19051-19059. CrossRef Medline

Kretz O, Fester L, Wehrenberg U, Zhou L, Brauckmann S, Zhao S, Prange-Kiel J, Naumann T, Jarry H, Frotscher M, Rune GM (2004) Hippocampal synapses depend on hippocampal estrogen synthesis. J Neurosci 24:5913-5921. CrossRef Medline

Legan SJ, Karsch FJ (1975) A daily signal for the LH surge in the rat. Endocrinology 96:57-62. CrossRef Medline

Luine VN (2014) Estradiol and cognitive function: past, present and future. Horm Behav 66:602-618. CrossRef Medline

Merchenthaler I, Görcs T, Sétáló G, Petrusz P, Flerkó B (1984) Gonadotropin-releasing hormone $(\mathrm{GnRH})$ neurons and pathways in the rat brain. Cell Tissue Res 237:15-29. Medline

Prange-Kiel J, Fester L, Zhou L, Lauke H, Carrétero J, Rune GM (2006) Inhibition of hippocampal estrogen synthesis causes region-specific downregulation of synaptic protein expression in hippocampal neurons. Hippocampus 16:464-471. CrossRef Medline

Prange-Kiel J, Schmutterer T, Fester L, Zhou L, Imholz P, Brandt N, Vierk R, Jarry H, Rune GM (2013) Endocrine regulation of estrogen synthesis in the hippocampus? Prog Histochem Cytochem 48:4964. CrossRef Medline

Prange-Kiel J, Wehrenberg U, Jarry H, Rune GM (2003) Para/autocrine regulation of estrogen receptors in hippocampal neurons. Hippocampus 13:226-234. CrossRef Medline

Roa J, Castellano JM, Navarro VM, Handelsman DJ, Pinilla L, TenaSempere M (2009) Kisspeptins and the control of gonadotropin secretion in male and female rodents. Peptides 30:57-66. CrossRef Medline

Roa J, Vigo E, Castellano JM, Gaytan F, Navarro VM, Aguilar E, Dijcks FA, Ederveen AG, Pinilla L, van Noort PI, Tena-Sempere M (2008) Opposite roles of estrogen receptor (ER)-alpha and ERbeta in the modulation of luteinizing hormone responses to kisspeptin in the female rat: implications for the generation of the preovulatory surge. Endocrinology 149:1627-1637. CrossRef Medline

Rosati F, Sturli N, Cungi MC, Morello M, Villanelli F, Bartolucci G, Finocchi C, Peri A, Serio M, Danza G (2011) Gonadotropinreleasing hormone modulates cholesterol synthesis and steroidogenesis in SH-SY5Y cells. J Steroid Biochem Mol Biol 124:77-83. CrossRef
Schang AL, Ngô-Muller V, Bleux C, Granger A, Chenut MC, Loudes C, Magre S, Counis R, Cohen-Tannoudji J, Laverrière JN (2011) $\mathrm{GnRH}$ receptor gene expression in the developing rat hippocampus: transcriptional regulation and potential roles in neuronal plasticity. Endocrinology 152:568-580. CrossRef Medline

Skinner DC, Caraty A (2002) Measurement and possible function of $\mathrm{GnRH}$ in cerebrospinal fluid in ewes. Reprod Suppl 59:25-39. Medline

Smith CC, Vedder LC, McMahon LL (2009) Estradiol and the relationship between dendritic spines, NR2B containing NMDA receptors, and the magnitude of long-term potentiation at hippocampal CA3-CA1 synapses. Psychoneuroendocrinology 34:Suppl 1:S130-S142. CrossRef

Smith JT, Cunningham MJ, Rissman EF, Clifton DK, Steiner RA (2005) Regulation of Kiss1 gene expression in the brain of the female mouse. Endocrinology 146:3686-3692. CrossRef Medline

Spencer JL, Waters EM, Romeo RD, Wood GE, Milner TA, McEwen BS (2008) Uncovering the mechanisms of estrogen effects on hippocampal function. Front Neuroendocrinol 29:219-237. CrossRef Medline

Tabatadze N, Sato SM, Woolley CS (2014) Quantitative analysis of long-form aromatase mRNA in the male and female rat brain. PLoS One 9:e100628

Terasawa E, Kenealy BP (2012) Neuroestrogen, rapid action of estradiol, and GnRH neurons. Front Neuroendocrinol 33:364-375. CrossRef Medline

Tuscher JJ, Szinte JS, Starrett JR, Krentzel AA, Fortress AM, Remage-Healey L, Frick KM (2016) Inhibition of local estrogen synthesis in the hippocampus impairs hippocampal memory consolidation in ovariectomized female mice. Horm Behav 83:60-67. CrossRef Medline

Wang L, Chadwick W, Park SS, Zhou Y, Silver N, Martin B, Maudsley $S$ (2010) Gonadotropin-releasing hormone receptor system: modulatory role in aging and neurodegeneration. CNS Neurol Disord Drug Targets 9:651-660. CrossRef

Weesner GD, Pfaff DW (1994) Disruption of estrous cyclicity following administration of a luteinizing hormone-releasing hormone antagonist to the preoptic area of the rat. Biol Reprod 50:11781182. Medline

Woolley CS, Gould E, Frankfurt M, McEwen BS (1990) Naturally occurring fluctuation in dendritic spine density on adult hippocampal pyramidal neurons. J Neurosci 10:4035-4039. Medline

Zhang G, Li J, Purkayastha S, Tang Y, Zhang H, Yin Y, Li B, Liu G, Cai D (2013) Hypothalamic programming of systemic ageing involving IKK-beta, NF-kappaB and GnRH. Nature 497:211-216. CrossRef Medline 